\title{
Spatial and Temporal Analyses of FGF9 Expression During Early Pregnancy
}

\author{
Sandra Šućurovića Tamara Nikolića Jan J. Brosens ${ }^{b} \quad$ Biserka Mulac-Jeričevića \\ aDepartment of Physiology and Immunology, Faculty of Medicine, University of Rijeka, Rijeka, Croatia, \\ ${ }^{b}$ Division of Biomedical Sciences, Warwick Medical School, Coventry CV2 2DX, United Kingdom
}

\section{Key Words}

Fibroblast growth factor 9 (FGF9) • Fibroblast growth factor receptor (FGFR) • Implantation • Angiogenesis

\begin{abstract}
Background: Fibroblast growth factors (FGFs), in complex with their receptors (FGFRs), regulate a broad spectrum of biological functions including cellular proliferation, survival, migration, and differentiation. In human endometrial stromal cells, FGF9 is regulated with estrogen (E). Methods/ Results: First, we report that in uterus tissue of ovariectomized wild type mice, FGF9 is present in three isoforms and is regulated with E. Second, we found that during periimplantation, Fgf9 expression reached its peak at day 4.5 of pregnancy. Immunofluorescence analyses demonstrated overlapping FGF9 and COX2 expression surrounding the blastocyst attachment site. Next, we identified FGF9- and CD31-positive cells as a part of the microvessels; however, expression was localized to a distinct population of cells. Finally, our data showed synchronized, spatial expression of FGF9 on the luminal epithelium with FGFR2 present on the trophectoderm. Conclusion: Our data suggest that FGF9 is a crucial factor required to establish the appropriate microenvironment for successful implantation and the maintenance of pregnancy.

(C) 2017 The Author(s)

Published by S. Karger AG, Basel
\end{abstract}

\section{Introduction}

The steroid hormones estrogen (E) and progesterone (P), through their cognate receptors estrogen receptor (ER) and progesterone receptor (PR), prepare the uterus for pregnancy [1,2]. The transcriptional activity of PR and ER leads to the synthesis of cytokines, growth factors, lipid mediators, and genes that control the dynamics of uterine transition to a receptive state and the establishment of pregnancy [2,3]. In mice, the window of uterine receptivity corresponds to the P-mediated downregulation of ER activity in the uterine luminal epithelium (LE). At day 4 of pregnancy, in coordination with P, a short surge of $E$ is nidatory for embryo attachment and implantation [1]. Suppression of ER-mediated proliferative activity by PR is mandatory for implantation and the establishment of pregnancy [4]. A recent study showed that the anti-proliferative activity of $\mathrm{P}$ in the uterine epithelium 
is mediated by heart and neural crest derivatives expressed transcript 2 (HAND2). Specific deletion of Hand2 in postnatal uteri [5] results in infertility and increased expression of several fibroblast growth factors $(\mathrm{Fgfs})$.

The vertebrate FGF family consists of 22 heparin-binding polypeptide growth factors. Most FGFs are mitogens and stimulate various cellular functions including migration, proliferation, and differentiation [6,7]. These activities are critical for a wide variety of physiological and pathological processes including embryonic development, angiogenesis, and tumorigenesis [8]. The biological function of FGFs is mediated by signaling through transmembrane tyrosine kinases receptors (FGFR) that are encoded by four distinct genes (Fgfr1-Fgfr4) [9]. In addition to the membrane localization of FGFRs, FGF induced cellular differentiation was found to be accompanied by the nuclear translocation of FGFRs [10].

In the uterus, components of the FGF signaling pathway can act as paracrine and/or autocrine mediators of epithelial-stromal interactions. Paracrine activation of FGFRs induces proliferation of the luminal epithelium in the uterus [11, 12]. Mice with uterine-specific Hand2 deletions failed to suppress the expression of Fgf1, Fgf2, Fgf9, and Fgf18 on day 3.5 of pregnancy [5]. A previous study demonstrated dynamic changes in FGF2 expression during peri-implantation [13]. In addition, FGF9 is a survival and mitogenic factor that is induced in endometrial cells by $\mathrm{E}$ and prostaglandins (PGs) $[14,15]$.

FGF9 is widely expressed in mouse embryos [16]. Ablation of Fgf9 alleles leads to lethality at the neonatal stage mainly due to malformations of the lung, in addition to causing male-to-female sex reversal [17]. To date, the expression of FGF9 and its receptors during peri-implantation has not been investigated. In this study, we report the spatial and temporal analyses of FGF9 expression during early pregnancy. We first compared the expression of P-regulated FGFs at day 2.5, 4.5, and 7.5 of pregnancy, and found that only Fgf9 and Fgf2 expression changed significantly during peri-implantation. We found that the expression of Fgf2 mRNA was highest at day 7.5 of pregnancy, whereas Fgf9 expression peaked at day 4.5 of pregnancy when implantation takes place.

\section{Materials and Methods}

\section{Animals and tissue collection}

All experimental and surgical procedures complied with the Guide of Care and Use of Laboratory Animals and were approved by the ethical committee of the University of Rijeka Faculty of Medicine and Ministry of Agriculture. Mice (BALB/c) were housed in humidity $(55 \pm 10 \%)$ and temperature $\left(22 \pm 2{ }^{\circ} \mathrm{C}\right)$ controlled rooms with a 12-hour light-dark cycle with free access to food and water.

Wild-type females (10-12-weeks old) were housed with fertile males; the day that the vaginal plug was observed was considered day 0.5 of pregnancy. The animals were sacrificed by cervical dislocation on day 2.5, 4.5, and 7.5 of pregnancy. Implantation sites at day 4.5 of pregnancy were visualized by intravenous injection ( $0.1 \mathrm{ml} /$ mouse) of Chicago blue B dye (Sigma Aldrich, Taufkirchen, Germany) solution (in 1\% saline). A discrete blue band represented the implantation site. One uterine horn was fixed in $4 \%$ paraformaldehyde and the other was frozen at $-80^{\circ} \mathrm{C}$ for RNA or protein isolation. For reverse transcriptionreal-time-polymerase chain reaction experiments and western blot analysis, the conceptuses on day 7.5 of pregnancy were carefully dissected out of the implantation site. To analyze protein expression during implantation, implantation and non-implantation sites were separated.

Wild-type mice (BALB/c) were ovariectomized [18] (from 6-8-week old animals) and allowed to rest for 2 weeks before hormonal treatment. Mice ( $n=3 /$ treatment) were given daily subcutaneous injections of sesame oil (vehicle), sesame oil containing E (250 ng), and sesame oil containing E and P (EP) (250 ng / 2.5 $\mathrm{mg}$ ) for 4 days. Uterus tissues were frozen at $-80^{\circ} \mathrm{C}$ for mRNA or protein isolation.

\section{Immunofluorescence}

Uterine sections $(5 \mu \mathrm{m})$ were prepared from tissues that were fixed in $4 \%$ (wt/vol) paraformaldehyde and paraffin-embedded. The sections were deparaffinized, rehydrated in graded concentrations of ethanol, and subjected to heat-induced antigen retrieval (10 $\mathrm{mM}$ sodium citrate, $\mathrm{pH}$ 6.0). The slides were then 


\section{Cellular Physiology Cell Physiol Biochem 2017;42:2318-2329 \begin{tabular}{l|l|l} 
and Biochemistry Published online: August 17, 2017 & $\begin{array}{l}\text { (c) } 2017 \text { The Author(s). Published by S. Karger AG, Basel } \\
\text { www.karger.com/cpb }\end{array}$
\end{tabular}

washed in PBS, pre-incubated in 1\% bovine serum albumin (BSA, Affymetrix, Santa Clara, CA, USA) in PBS containing $0.001 \% \mathrm{NaN}_{3}$ for 1 hour at room temperature. The following primary antibodies were used: mouse monoclonal FGF9 (D-8) IgG 3 (1:100 dilution, Santa Cruz Biotechnology, Santa Cruz, CA, USA), rabbit monoclonal Cox2 (SP21) IgG (1:200 dilution, Thermo Scientific, Waltham, MA, USA), rabbit monoclonal CD31 (PECAM-1) (D8V9E) IgG (1:100 dilution, Cell Signaling, Leiden, Netherlands), rabbit polyclonal FGFR3 (C-15) IgG (1:200 dilution, Santa Cruz Biotechnology, Santa Cruz, CA, USA), and rabbit polyclonal FGFR-2 (Bek, C-17) IgG (1:50 dilution, Santa Cruz Biotechnology, Santa Cruz, CA, USA). Primary antibodies were diluted in $1 \%$ BSA in PBS containing $0.001 \% \mathrm{NaN}_{3}$ and incubated with tissue sections overnight at $4{ }^{\circ} \mathrm{C}$ in a humid environment. To visualize immunocomplexes, Alexa donkey anti-rabbit $594 \mathrm{~nm}$ (1:500 dilution,

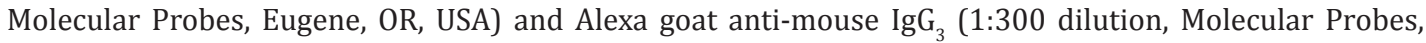
Eugene, OR, USA) were used. Secondary antibodies were diluted in blocking solution and incubated with tissue sections in the dark for 1 hour at room temperature in a humid environment. Nuclei were visualized with DAPI (Vector Laboratories, Burlingame, CA, USA). Images were captured using an Olympus (Tokyo, Japan) imaging system equipped with a DP71CCD camera, and CellF imaging software was used. Images were edited using Photoshop CS6 (Adobe, San Jose, CA, SAD).

\section{RNA isolation and real-time RT-PCR analysis}

Total RNA was isolated from uterine tissues ( $\mathrm{n}=3$ per pool) using Trizol (Invitrogen, Carlsbad, CA, USA) according to the manufacturer's protocol. The RNA was reserve transcribed and gene levels were quantified by quantitative real time-PCR (qRT-PCR) using the ABI Prism 7300 detection system (Applied Biosystems, Foster City, CA, USA). This procedure was independently repeated three times. Oligonucleotide primers for mouse Fgf1 (forward 5'-TTTATACGGCTCGCAGACAC-3'; reverse 5'-CGCTTACAGCTCCCGTTCTT-3'), Fgf2 (forward 5'-GGCTGCTGGCTTCTAAGTGT-3'; reverse 5'-GTCCCGTTTTGGATCCGAGT-3'), Fgf9 (forward 5'-GCAGTCACGGACTTGGATCA-3'; reverse 5'-AATTCCAGAATGCCGAAGCG-3'), Fgf18 (forward 5'- CCTGCACTTGCCTGTGTTTA-3'; reverse 5'- GCTGCTTCCGACTCACATCA-3') and Cox2 (forward 5'-GGGCCATGGAGTGGACTTAAA-3'; reverse 5'- TGCAGGTTCTCAGGGATGTG-3') were obtained from Metabion (Steinkirschen, Germany). Relative mRNA levels were determined after normalization to mouse Gapdh expression [19].

\section{Western blotting}

Protein extracts were obtained from uterine tissues $(n=3)$ using RIPA buffer (Thermo Scientific, Waltham, MA, USA). The concentration was determined using a Bradford protein assay kit (BioRad, Hercules, CA, USA). Proteins were separated by $12 \%$ sodium dodecyl sulfate polyacrylamide gel electrophoresis (SDS-PAGE), under reducing conditions, and then transferred onto a nitrocellulose membrane (BioRad, Hercules, CA, USA). The membrane was blocked with 5\% BSA in tris-buffered saline (TBS) with $0.05 \%$ tween-20 (TBST) and incubated with rabbit anti-FGF9 IgG antibody (1:2000 dilution, Abcam, Cambridge, UK) followed by incubation with species-specific HRP-conjugated secondary antibodies. In accordance with the datasheet, this antibody recognizes three species of FGF9, specifically, 30, 29, and $25 \mathrm{kDa}$. Mouse anti- $\beta$-actin (1:160 000 dilution, Millipore, Billerica, MA, USA) was used as a control of protein loading. For detection, membranes were incubated with Amersham ECL Prime (GE Healthcare, Little Chalfont, UK), and scanned with an Alliance 4.0 imager (Uvitec, Cambridge, UK).

\section{Statistical analysis}

All data are reported as mean \pm S.E.M. and were analyzed by a Student's $t$ test and one-way ANOVA followed by the Scheffe post-hoc method. $\mathrm{P}<0.05$ was considered significant. All statistical analyses were performed using STATISTICA 10 (StatSoft Inc, Tulsa, OK, SAD).

\section{Results}

Expression of Fgfs in the uterus during early pregnancy

Gene expression profiling on day 3.5 of pregnancy revealed elevated expression of mRNA corresponding to several FGF members in mice with uterine-specific Cre-mediated ablation of Hand2 [5]. To further assess the role of FGFs, we determined the mRNA expression of 


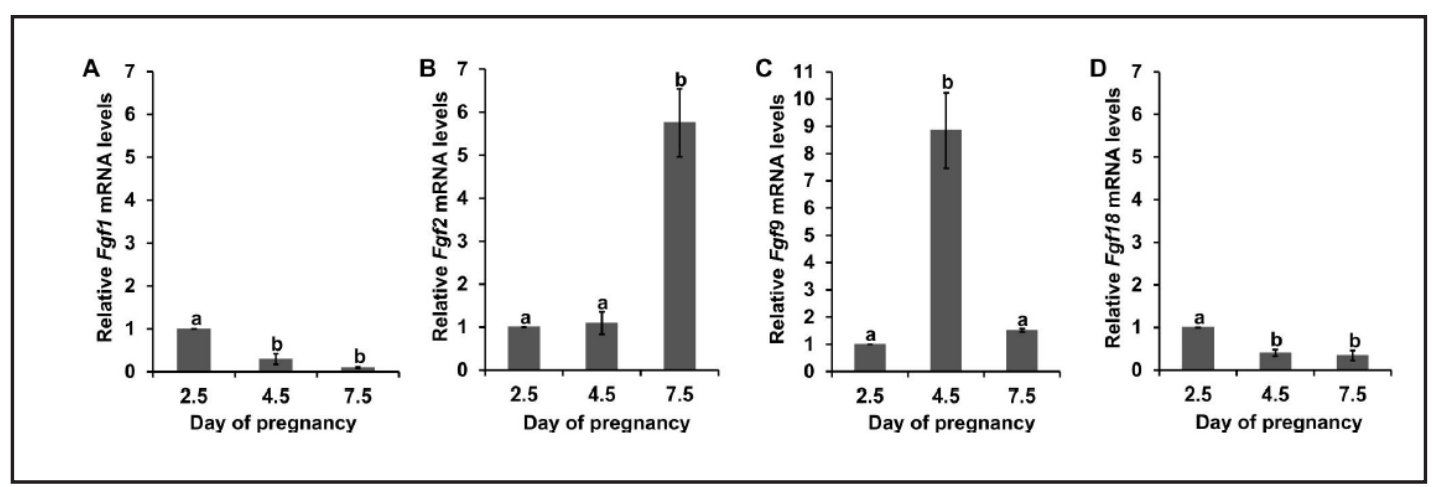

Fig. 1. Relative levels of $F g f 1$ (A), $F g f 2$ (B), $F g f 9$ (C) and $F g f 18$ (D) mRNA expression in uteri during early pregnancy. Mice were bred and pregnancy was indicated by the appearance of a vaginal plug (day 0.5 of pregnancy), after which animals were sacrificed at the indicated time points. Uterine horn tissue was removed and real time reverse-transcription PCR was performed for quantification of gene expression. Bars represent mean \pm SEM and those with different letters are significantly $(\mathrm{p}<0.05)$ different based on an ANOVA followed by the Scheffe post-hoc method.

Fgf1, Fgf2, Fgf9, and Fgf18 on days 2.5, 4.5, and 7.5 of pregnancy (Fig. 1). With pregnancy progression, we observed significant changes in the expression levels of mRNA encoding FGF2 and FGF9. Fgf9 mRNA expression reached its peak at day 4.5 of pregnancy when embryo attachment induces the initiation of decidualization (Fig. 1C). With the development of the mesometrial decidua (basalis) at day 7.5 of pregnancy, a decline in Fgf9 mRNA expression occurred (Fig. 1C). Whereas Fgf9 mRNA decreased, Fgf2 mRNA expression reached its maximum (Fig. 1B) at day 7.5 of pregnancy. These data strongly suggest that FGF9 and FGF2 have distinct but overlapping roles during peri-implantation; specifically, FGF9 dominates during implantation and primary decidualization, whereas FGF2 activity is involved in the control of secondary decidua zone formation.

\section{FGF9 protein expression during peri-implantation}

To the best of our knowledge, spatiotemporal expression of FGF9 during the periimplantation period in mouse uteri has not been analyzed previously. Therefore, our next aim was to determine the localization of FGF9 on day 2.5, 4.5, and 7.5 of pregnancy. For this, we employed immunohistochemistry for the fluorescent detection for FGF9, and counterstaining with DAPI. At day 2.5 of pregnancy, FGF9 was primarily localized to the apical surface of epithelial cells but was also found in the glandular epithelium (GE) and some stromal cells (Fig. 2A, I-II). Next, on day 4.5 of pregnancy, when embryo attachment and implantation commences, we utilized a vascular permeability assay to identify implantation sites [18]. The implantation sites, detected as distinct blue bands, were dissected and prepared for analyses as described in the materials and methods section. The robust fluorescent staining for FGF9 was identified on the apical surface of the LE surrounding the implanting conceptus. Staining for FGF9 was also present throughout the cytoplasm of the LE, on the apical surface of the glandular epithelium (GE), and subpopulation of stromal cells (Fig. 2A, III-IV). By day 7.5 of pregnancy, FGF9 protein levels declined, but remained localized to the apical surface of the residual LE (Fig. 2A, V-VI).

Next, to analyze FGF9 distribution during early pregnancy we prepared protein extracts from uteri at day 2.5, 4.5, and 7.5 of pregnancy for western blot analyses (Fig. 2B). At day 4.5 of pregnancy, protein extracts were prepared separately from dissected uterine sections labeled with Chicago blue (implantation site) and from those that did not retain the blue color (non-implantation site). Our results revealed that of the three expected FGF9 protein species $(25,29$, and $30 \mathrm{kDa})[20]$, the $25-\mathrm{kDa}$ FGF9 protein species was not detected in the uterus during early pregnancy (Fig. 2B). Although we detected FGF9 protein species of 29 and 30 $\mathrm{kDa}$ at all analyzed time points of pregnancy, our result indicates that the $30 \mathrm{kDa}$ form was 


\section{Cellular Physiology Cell Physiol Biochem 2017;42:2318-2329

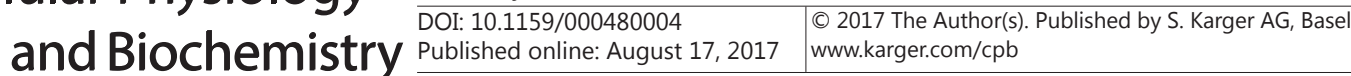 \\ Šućurović et al.: FGF9 Expression during Early Pregnancy}

Fig. 2. Expression of FGF9 during peri-implantation. (A) Localization of FGF9 protein in mouse uteri at day 2.5 (I-II), 4.5 (III-IV), and 7.5 (V-VI) of pregnancy. Immunofluorescence staining with a mouse monoclonal antibody to FGF9 (green) is shown. Nuclei were counterstained with DAPI (blue). The arrow in panel IV shows an embryo at the implantation site. These results are representative of at least three independent samples. Scale bars $=200 \mu \mathrm{m}$ (I, III, V) and $20 \mu \mathrm{m}$ (II, IV, VI); dpc: days post coitum; $\left(^{*}\right)$ represents region at higher magnification. (B) FGF9 protein expression during early pregnancy. FGF9 protein was present as two separate bands of approximately 30 and $29 \mathrm{kDa}$. Actin was used as a loading control; NIS: non-implantation site; IS: implantation site. These results are representative of three independent samples.

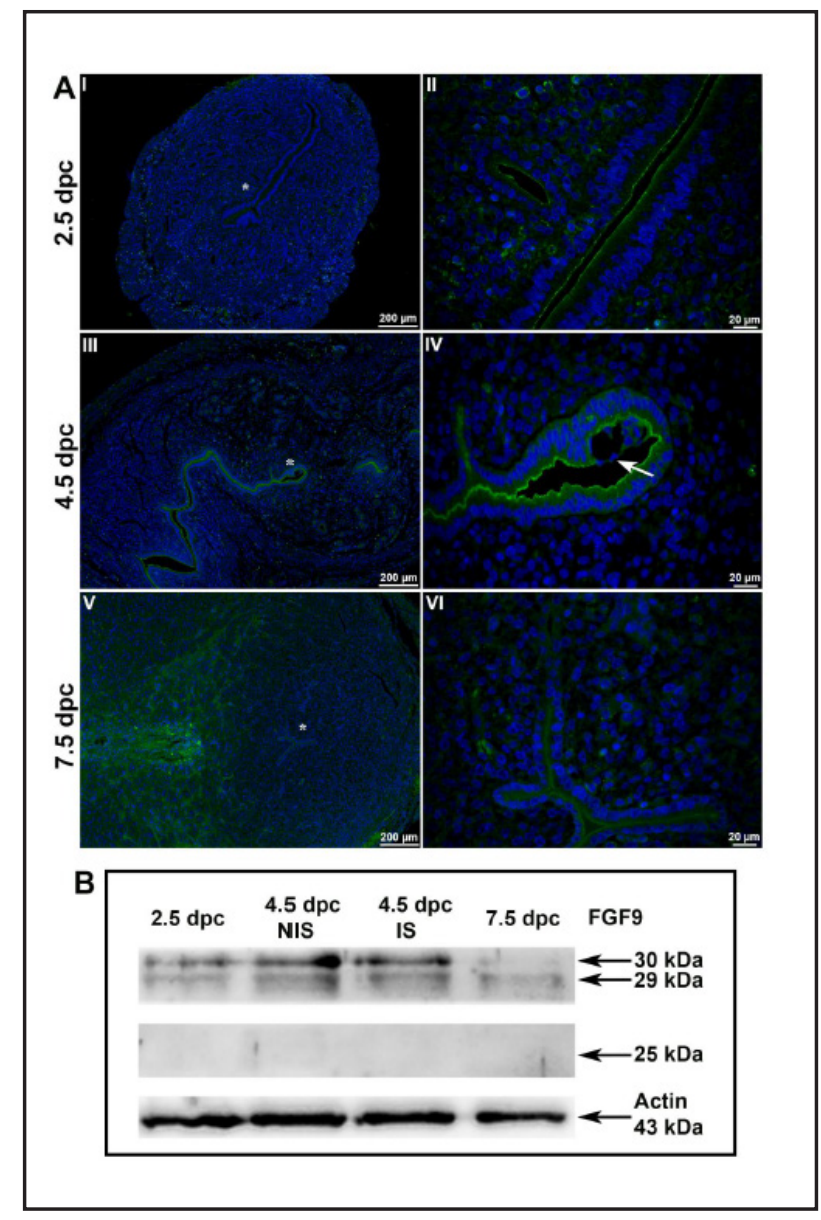

Fig. 3. Analysis of FGF9 expression in the uterus of ovariectomized mice. Animals were treated with sesame oil as a control (C), estrogen (E), or estrogen/progesterone (EP). FGF9 was present as three separate bands of approximately 30, 29, and $25 \mathrm{kDa}$. Actin was used as a loading control. These results are representative of three independent samples. No signals were observed when primary antibodies specific for FGF9 were replaced with whole rabbit IgG, confirming antibody specificity (data not shown).

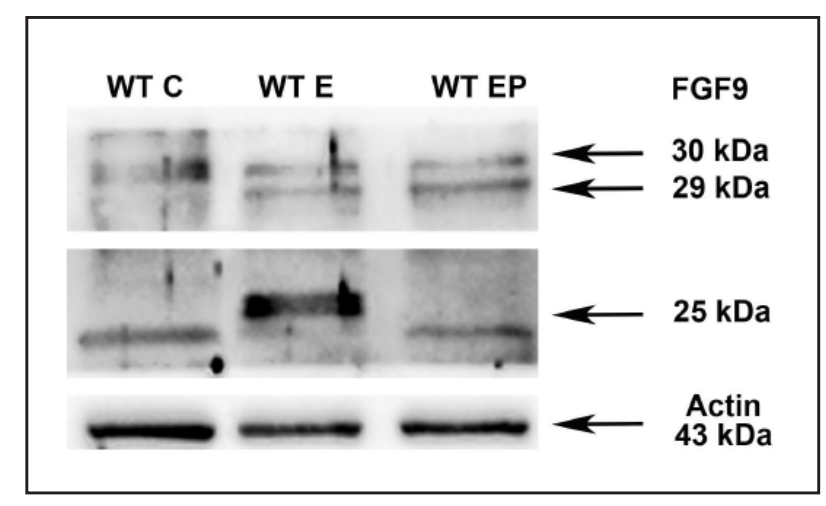

dynamically expressed, whereas expression of the $29 \mathrm{kDa}$ form was constant. Stronger FGF9 expression was detected at day 4.5 of pregnancy, with no appreciable difference between implantation and non-implantation sites (Fig. 2B).

We also examined FGF9 expression in ovariectomized mouse uteri after treatment with E, EP, and sesame oil as a control (Fig. 3). In addition to the 29 and $30 \mathrm{kDa}$ bands, an additional 25-kDa band was present after E treatment (Fig. 3). Altogether, our results imply that FGF9 activity could be necessary for embryo implantation.

\section{KARGER}




\section{Cellular Physiology Cell Physiol Biochem 2017;42:2318-2329 \begin{tabular}{l|l} 
and Biochemistry Published onlıne: August 17, 2017 & $\begin{array}{l}\text { C) } 2017 \text { The Author(s). Published by S. Karger AG, Basel } \\
\text { www.karger.com/cpb }\end{array}$
\end{tabular}

\section{Expression of FGF9 at the implantation site}

Tightly controlled spatial and temporal cellular and molecular changes induced by E and $\mathrm{P}$ are required for establishing the window of implantation. Consequences of ER $\alpha$ ablation include partial loss of PR expression and complete loss of embryo attachment and implantation [21, 22]. Previously, it was reported that along with E, PGE2 induces the expression of FGF9 [23, 24]. In addition, the rate-limiting step in PGE2 synthesis is regulated by COX2 [25]. In mice, genetic ablation of COX2 results in infertility because of defective implantation and decidualization [26]. Earlier analyses using in situ hybridization and immunohistochemistry suggested that COX2 expression was restricted to the stroma surrounding the implantation site at day 4.5 of pregnancy [27].

Here we analyzed Cox2 and Fgf9 mRNA and protein expression using qPCR and immunostaining with indirect immunofluorescence. We found a substantial increase in Cox2 mRNA expression at the site of implantation, when compared to that at the nonimplantation site (Fig. 4D). Immunostaining for COX2 indicated that at day 4.5 of pregnancy, very strong expression of COX2 was present in stromal cells proximal to the implanting embryo (Fig. 4, A-C). In addition, at the same point of pregnancy, our analyses indicated that lower levels of COX2 were also present throughout LE (Fig. 4B). Also, at day 4.5 of pregnancy, immunofluorescence indicative of FGF9 (Fig. 4, E-G) was found in the LE, but not in COX2-positive stromal cells (Fig. 4C). Contrary to Cox2 mRNA, Fgf9 mRNA expression was not significantly different between implantation and non-implantation sites (Fig. $4 \mathrm{H}$ ). Furthermore, studies with COX2 mutant mice showed that COX2-derived PGs are important

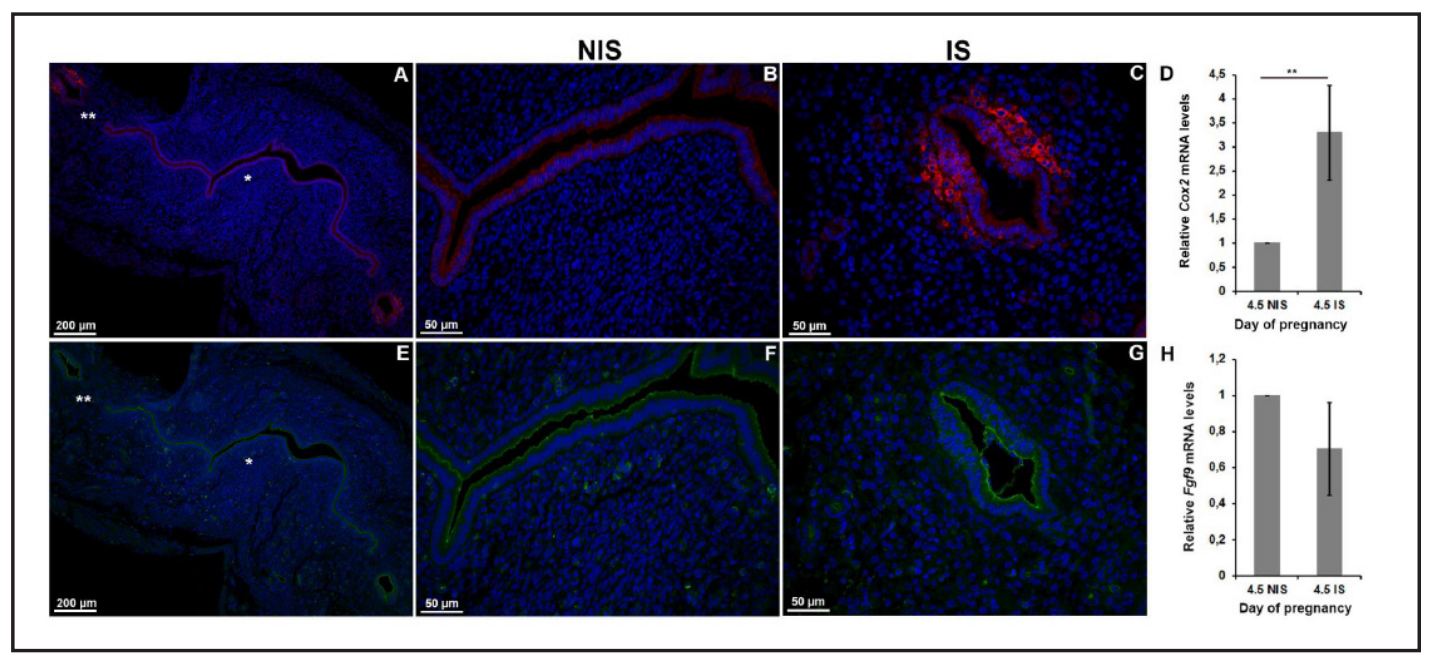

Fig. 4. Distribution of COX2 and FGF9 protein at day 4.5 of pregnancy. (A\&E) Expression of COX2 and FGF9 at day 4.5 of pregnancy. (B\&F) Localization of COX2 and FGF9 at non-implantation site. (C\&G) Localization of COX2 and FGF9 at implantation site around blastocyst attachment. Mice were sacrificed at the indicated time point and uterine tissues were isolated. Immunofluorescence staining was performed with a rabbit monoclonal antibody to COX2 (red) and mouse monoclonal antibody to FGF9 (green). Nuclei were counterstained with DAPI (blue). These results are representative of at least three independent samples. Scale bars $=200 \mu \mathrm{m}(\mathrm{A}, \mathrm{E})$ and $50 \mu \mathrm{m}(\mathrm{B}, \mathrm{C}, \mathrm{F}, \mathrm{G}) ;$ dpc: days post coitum; NIS: non-implantation site; IS: implantation site $\left.{ }^{*}\right)$ represents region at higher magnification at non-implantation site; $\left.{ }^{(* *}\right)$ represents region at higher magnification at implantation site. Difference in relative levels of Cox2 and Fgf9 mRNA expression between non-implantation and implantation site (D\&H). Mice were bred and pregnancy was indicated by the appearance of a vaginal plug, after which animals were sacrificed at day 4.5 of pregnancy. Implantation sites at day 4.5 of pregnancy were visualized by intravenous injection of Chicago blue B dye. The implantation sites, detected as distinct blue bands, were dissected and prepared separately from the non-implantation site for RNA isolation. Real time reverse-transcription PCR was performed for quantification of gene expression. Bars represent mean \pm SEM and those with ${ }^{* *}$ are significantly $(\mathrm{p}<0.01)$ different based on the Student's $\mathrm{t}$ test.

\section{KARGER}




\section{Cellular Physiology Cell Physiol Biochem 2017;42:2318-2329

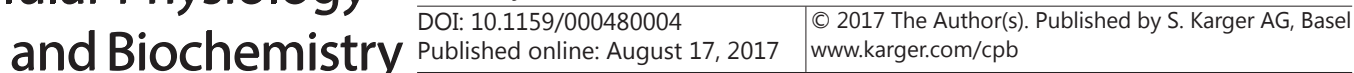 \\ Šućurović et al.: FGF9 Expression during Early Pregnancy}

for vascular permeability and angiogenesis during implantation and decidualization [28]. Therefore, we applied triple immunofluorescence to analyze the relationship between FGF9 and COX2 at the implantation site (Fig. 5A \& B). We found a strong signal for FGF9 and COX2 in cells surrounding the implantation site. In the LE, FGF9 was detected on the apical site of the cells, whereas COX2-positive cells were present in the stroma as well as in some cells of the LE. Interestingly, in the LE, COX2-positive cells were localized to the site of immediate contact between the embryo and the LE (Fig. 5A \& B). This indicates that local COX2 enzymatic activity should induce adequate expression of PGs for stimulation of FGF9 activity at the site of embryo implantation.

As aforementioned, one of the first signs of implantation is increased endometrial vascular permeability at the site of embryo apposition [29]. In addition, it is known that FGFs are strong angiogenic inducers [30]. Previously, it was reported that FGF9 delivery during angiogenesis produces durable, vasoresponsive microvessels wrapped by smooth muscle cells [31]. Therefore, we hypothesized that FGF9 might be associated with angiogenesis during early pregnancy. For these analyses, we used an antibody specific for FGF9 and a marker of endothelial cells, specifically, anti-CD31 (PECAM-1). With triple-labeling immunofluorescence, we identified that FGF9- and CD31-positive cells were part of the microvasculature, but localized to a distinct population of cells (Fig. 5C \& D). Therefore, FGF9-positive cells could represent a mural population of cells. Mural cells, consisting of vascular smooth muscle cells and pericytes, cover endothelial cells to regulate vascular stability and homeostasis [32]. This finding indicates that FGF9 could have an important role in microvessel maturation during angiogenesis at the implantation site.

\section{Expression of FGF9 and its receptors at the implantation site}

The biological activity of FGFs is mediated by four different tyrosine kinase receptors (FGFR1-4). To exert its effect, FGF9 is known to bind FGFR2, FGFR3, and FGFR4 [33]. We

Fig. 5. FGF9 expression at the implantation site at day 4.5 of pregnancy. (A\&B) Co-expression of FGF9 and COX2 at the implantation site at day 4.5 of pregnancy. Mice were sacrificed at the indicated time point and uterine tissues were isolated. Triple immunofluorescence staining was performed with a mouse monoclonal antibody to FGF9 (green) and a rabbit monoclonal antibody to COX2 (red). Nuclei were counterstained with DAPI (blue). (C\&D) Analysis of FGF9 co-expression with CD31 (PECAM-1) at the implantation site at day 4.5 of pregnancy. Triple immu-

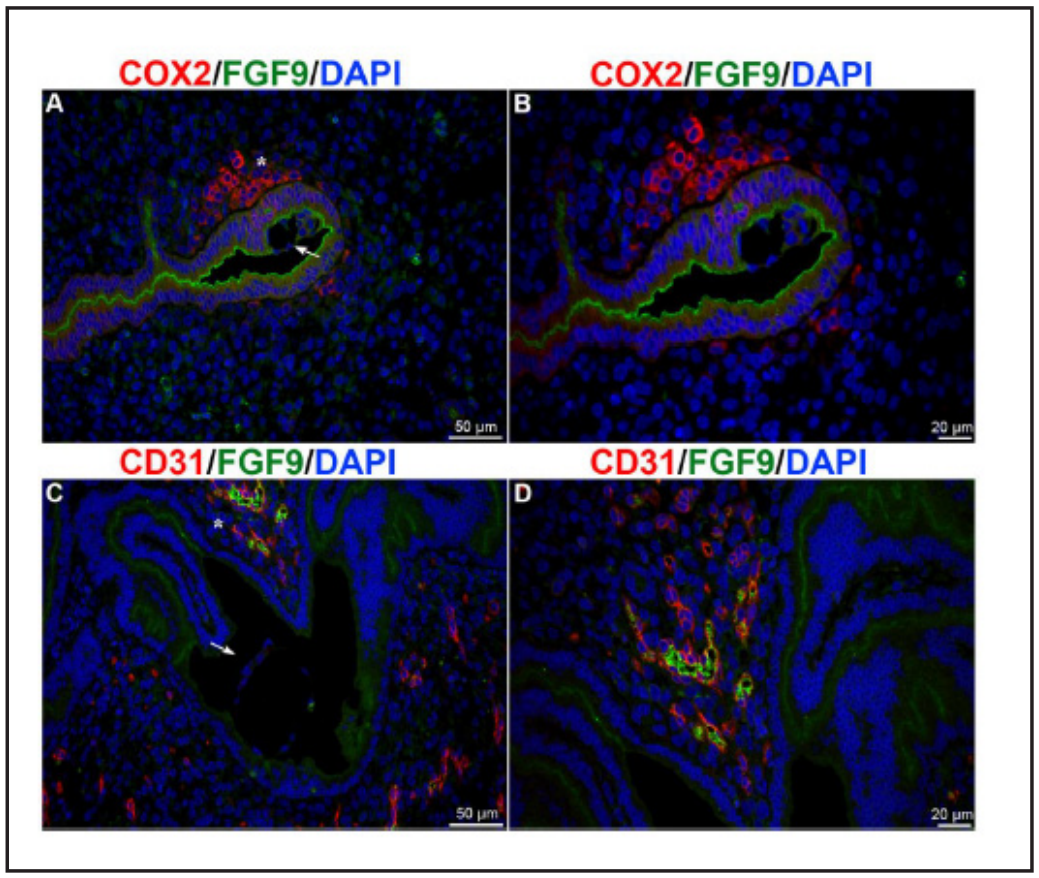
nofluorescence staining was performed with a mouse monoclonal antibody to FGF9 (green) and a rabbit monoclonal antibody to CD31 (red). Nuclei were counterstained with DAPI (blue). The arrows in panel A and $\mathrm{C}$ depict the embryo; dpc: days post coitum; $\left(^{*}\right)$ represents the region at a higher magnification. These results are representative of at least three independent samples. Scale bars represent $50 \mu \mathrm{m}(\mathrm{A}, \mathrm{C})$ and 20 $\mu \mathrm{m}(\mathrm{B}, \mathrm{D})$. 


\section{Cellular Physiology and Biochemistry}

Fig. 6. Localization of FGF9 and its receptors, FGFR2 and FGFR3, at the implantation site at day 4.5 of pregnancy. (A) Triple immunofluorescence staining was performed using a mouse monoclonal antibody specific for FGF9 (green) and a rabbit polyclonal antibody for FGFR2 (red). Nuclei

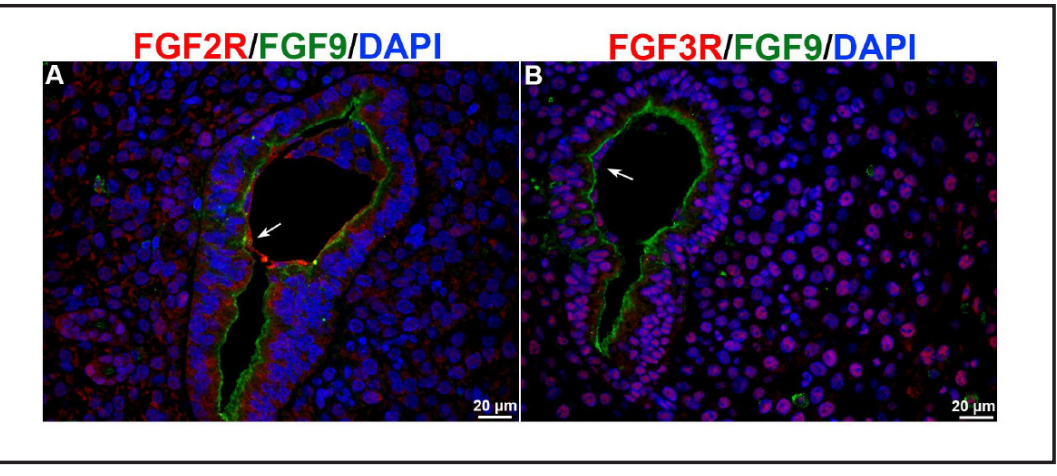
were counterstained with DAPI (blue). (B) Triple immunofluorescence staining was performed with a mouse monoclonal antibody for FGF9 (green) and a rabbit polyclonal antibody for FGFR3 (red). Nuclei were counterstained with DAPI (blue). The arrows in panel A and B indicate the trophectoderm of the embryo; dpc: day post coitum. These results are representative of at least three independent samples. Scale bars = $20 \mu \mathrm{m}$.

next analyzed the spatial relationship between FGF9 and FGFR2/FGFR3, which are known to bind FGF9 with high affinity [34,35], at the implantation site. Triple immunofluorescence staining using an antibody specific for FGF9 in combination with that recognizing FGFRs showed that FGFR2 localized to the cytoplasm (Fig. 6A), whereas FGFR3 was predominantly present in the nuclei (Fig. 6B) of stromal and epithelial cells. Strong immunofluorescence staining indicated the presence of FGF9 on the apical side of epithelial cells. In addition, intense staining for FGFR2, but not FGFR3, was present in the trophectoderm. Altogether, our results demonstrated synchronized spatial expression of FGF9 and its receptor, FGFR2. Therefore, FGF9-FGFR2 signaling could be important for communication between the uterine epithelium and trophoblast, which is necessary for embryo apposition and implantation.

\section{Discussion}

E-driven proliferation in the uterus is mediated by paracrine signaling involving FGFs $[11,15]$. P suppresses E-dependent proliferation in the epithelium, which is mandatory to establish the microenvironment required for successful implantation [36]. Our data provide evidence that expression of $F g f 2$ and $F g f 9$ peak at two distinct time points during pregnancy: Fgf9 at day 4.5 of pregnancy, when attachment and implantation commence, and Fgf2 at day 7.5 of pregnancy, corresponding to decidua formation. Previously, whole mount in situ hybridization data showed that Fgf2 expression appears in the stroma surrounding the implanting blastocyst and continues to increase with decidualization [13]. Our data presented here show for the first time that FGF9 expression is highly upregulated during implantation in the mouse uterus. Earlier, it was reported that FGF9 in human stromal cells is regulated by $\mathrm{E}$ [15].

Recent studies using chromatin immunoprecipitation followed by sequencing of enriched chromatin fragments showed that Fgf9 has an ER-, but not a PR, response element $[37,38]$. We assessed the effect of E and EP on FGF9 expression in ovariectomized mouse uteri, and our data showed the existence of three FGF9 isoforms detected as bands of 25, 29 , and $30 \mathrm{kDa}$. Only the 25 -kDa FGF9 species was strongly induced by E treatment. The existence of three protein species of FGF9, at 25, 29 and $30 \mathrm{kDa}$, was previously reported for FGF9 isolated from human glial cells [20]. Therefore, with more than $99 \%$ sequence identity between human and mouse FGF9 homologs, it is reasonable to assume that these heparin-binding proteins could be post-translationally processed in the same manner in the uteri of both species. It is known that in mice, at day 4 of pregnancy, a short surge of $E$ is

\section{KARGER}




\section{Cellular Physiology Cell Physiol Biochem 2017;42:2318-2329 \\ and Biochemistry Published online: August 17, 2017 \begin{tabular}{l|l} 
DOI: 10.1159/000480004 2017 The Author(s). Published by S. Karger AG, Basel \\
www.karger.com/cpb
\end{tabular} \\ Šućurović et al.: FGF9 Expression during Early Pregnancy}

mandatory for embryo attachment and implantation [1]. Surprisingly, the E-induced 25-kDa FGF9 isoform, detected in the uteri of ovariectomized mice, was absent from pregnant uteri during the peri-implantation period. The lack of this FGF9 protein species and the maximum expression of the other 29- and 30-kDa proteins at day 4.5 of pregnancy suggest that FGF9 isoforms have a selective role in endometrial functions.

Previously, it was shown that the COX2 product PGE2 induces FGF9, which promotes endometrial stromal cell proliferation [23]. Female mice with genetic ablation of Cox2 exhibit pleiotropic defects including impaired implantation and decidualization [26, 39]. The spatial-localized expression of COX2 around the attachment site could be a consequence of embryonic signaling through protease-activated epithelial $\mathrm{Na}^{+}$channel (ENaC), which results in $\mathrm{Ca}^{2+}$ influx and the induction of a COX2 and PGs surge [40, 41]. Our results suggest that at day 4.5 of pregnancy, PGs synthesized around the implantation site by COX2 might induce epithelial FGF9 expression. This upregulation of FGF9 signaling could be required to produce a highly specific, transient environment that is necessary for the functional window of implantation. As previously reported, FGF9 expression is regulated with E and PGE2 [14, 15]. PGE2 signaling is mediated by the EP3 receptor [23, 24]. In uterine stromal cells, the EP3 receptor is a product of the transcriptional activity of HOXA-10, and accordingly, the expression of EP3 is reduced in $H O X A-10^{\%}$ mice [42]. Recent reports revealed that in the endometrium of mice and humans, HOXA-10 is regulated by P [4]. Therefore, in the uterus, the activity of FGF9 could depend on a delicate balance between E and P activity.

One of the first signs of implantation is increased endometrial vascular permeability at the site of blastocyst attachment and penetration. This process is regulated with PGs [26]. In addition, it is known that FGFs have role in angiogenesis in the uterus [43]. Recent data showed that FGF9 delivery during angiogenesis produces durable, vasoresponsive microvessels wrapped by smooth muscle cells, and promotes new vascular maturation. In addition, the combination of FGF2 and FGF9 in Matrigel plugs implanted in mice resulted in a robust synergistic effect on microvessel formation [31]. Microvessels consist of a tubular endothelial-cell lining surrounded by supporting mural cells. Our data, based on triple immunofluorescence analysis of FGF9, CD31 (PECAM-1), and DAPI, showed that FGF9 is located in cells that are associated with microvessels; however, its expression does not overlap with CD31 in endothelial cells. Therefore, we speculate that FGF9-positive cells could be mural cells acting in a paracrine and autocrine fashion to stimulate microvessel maturation.

FGF9 binds with high affinity to FGFR2-IIIc and FGFR3-IIIc receptors [33]. Interestingly, FGFR3 was expressed in the nucleus of stromal cells and the LE surrounding the implantation site. Nuclear localization of FGFR3 has been reported for breast, bladder, and pancreatic cancer [44-46]. It has also been proposed that cellular mechanisms used by cells during implantation can be exploited by cancer cells to migrate through and invade tissues $[36,47]$. Therefore, in addition to progressing the understanding of the intricate mechanism of embryo implantation, further study of FGFR3 could also contribute to improved understanding of cellular and molecular events leading to metastasis. A recent study showed that postnatal uterine specific ablation of FGFR2 resulted in stratified LE and pregnancy loss during peri-implantation. This demonstrates a critical role for FGFR2 in proper post-natal uterine development as well as normal uterine function [12]. Further, it was established that FGF9FGFR2IIIc signaling in the uterine epithelium prevents epithelial stratification [12, 48]. The presence of FGFR2 was also previously detected in mouse blastocysts and was shown to play an important role in development during peri-implantation [49]. Furthermore, global deletion of Fgfr2 results in peri-implantation death and trophoblast arrest, suggesting that the mutant dies before a visible decidual reaction. FGFR2-deficient blastocysts induce increased capillary permeability, which is an indication of the first step of implantation, but without appropriate stromal decidualization. Hence, it appears that in the absence of FGFR2, uterine trophectoderm-induced decidualization is inadequate [50]. Implantation is an intricate process that requires a properly prepared endometrium and a functional embryo that is competent for implantation [41]. Our results, showing the expression of FGF9 in the 


\section{Cellular Physiology Cell Physiol Biochem 2017;42:2318-2329 \begin{tabular}{ll|l} 
and Biochemistry & $\begin{array}{l}\text { DOI: 10.1159/000480004 } \\
\text { Published online: August 17, } 2017\end{array}$ & $\begin{array}{l}\text { O 2017 The Author(s). Published by S. Karger AG, Basel } \\
\text { www.karger.com/cpb }\end{array}$ \\
\cline { 2 - 3 }
\end{tabular}

endometrium and the presence of FGFR2 in the trophectoderm, indicate that an FGF9-FGFR2 axis could be vital for the recognition of blastocysts that are competent for implantation.

\section{Conclusion}

In summary, our data suggest that in mice, FGF9 is a crucial factor required for establishing an appropriate microenvironment for successful implantation and for pregnancy establishment. Additional analyses of pathways through which FGF9 participates in angiogenesis and endometrium-embryo communication should contribute to the understanding of molecular mechanisms that underlay process of implantation. Many pathways involved in endometrial function during implantation are conserved in mice and humans. Therefore, better knowledge of the molecular mechanisms involved in the FGF9 regulation of implantation could conceivably contribute to understanding as well as treatment of infertility.

\section{Acknowledgements}

This work was supported by a grant from the Croatian science foundation (HRZZ 3432) (BMJ) and a grant from the University of Rijeka, Croatia 13.06.1.1.08 (BMJ). The authors gratefully acknowledge Tatjana Daka and Tihana Vujnović for technical assistance and Ksenija Tulić for administrative help.

\section{Disclosure Statement}

The authors of this manuscript declare that they have no conflicts of interests.

\section{References}

1 Cha J, Sun X, Dey SK: Mechanisms of implantation: strategies for successful pregnancy. Nat Med 2012;18:1754-1767.

2 Cha J, Dey SK: Cadence of procreation: orchestrating embryo-uterine interactions. Semin Cell Dev Biol 2014;34:56-64.

3 Tranguch S, Daikoku T, Guo Y, Wang H, Dey SK: Molecular complexity in establishing uterine receptivity and implantation. Cell Mol Life Sci 2005;62:1964-1973.

4 Large MJ, DeMayo FJ: The regulation of embryo implantation and endometrial decidualization by progesterone receptor signaling. Mol Cell Endocrinol 2012;358:155-165

5 Li Q Kannan A, DeMayo FJ, Lydon JP, Cooke PS, Yamagishi H, Srivastava D, Bagchi MK, Bagchi IC: The antiproliferative action of progesterone in uterine epithelium is mediated by Hand2. Science 2011;331:912-916.

-6 Yun YR, Won JE, Jeon E, Lee S, Kang W, Jo H, Jang JH, Shin US, Kim HW: Fibroblast growth factors: biology, function, and application for tissue regeneration. J Tissue Eng 2010;2010:218142.

-7 Itoh N, Ornitz DM: Fibroblast growth factors: from molecular evolution to roles in development, metabolism and disease. J Biochem 2011;149:121-130.

8 Beenken A, Mohammadi M: The FGF family: biology, pathophysiology and therapy. Nat Rev Drug Discov 2009;8:235-253.

-9 Eswarakumar VP, Lax I, Schlessinger J: Cellular signaling by fibroblast growth factor receptors. Cytokine Growth Factor Rev 2005;16:139-149.

10 Fearon AE, Gould CR, Grose RP: FGFR signalling in women's cancers. Int J Biochem Cell Biol 2013;45:28322842. 


\section{Cellular Physiology Cell Physiol Biochem 2017;42:2318-2329 \begin{tabular}{ll|l} 
and Biochemistry Published online: August 17, 2017 & $\begin{array}{l}\text { (c) } 2017 \text { The Author(s). Published by S. Karger AG, Basel } \\
\text { www.karger.com/cpb }\end{array}$
\end{tabular}

11 Fujimoto J, Hori M, Ichigo S, Tamaya T: Ovarian steroids regulate the expression of basic fibroblast growth factor and its mRNA in fibroblasts derived from uterine endometrium. Ann Clin Biochem 1997;34(Pt 1):9196.

\$2 Filant J, DeMayo FJ, Pru JK, Lydon JP, Spencer TE: Fibroblast growth factor receptor two (FGFR2) regulates uterine epithelial integrity and fertility in mice. Biol Reprod 2014;90:7.

13 Paria BC, Ma W, Tan J, Raja S, Das SK, Dey SK, Hogan BL: Cellular and molecular responses of the uterus to embryo implantation can be elicited by locally applied growth factors. Proc Natl Acad Sci U S A 2001;98:1047-1052.

14 Wu MH, Shoji Y, Chuang PC, Tsai SJ: Endometriosis: disease pathophysiology and the role of prostaglandins. Expert Rev Mol Med 2007;9:1-20.

15 Tsai SJ, Wu MH, Chen HM, Chuang PC, Wing LY: Fibroblast growth factor-9 is an endometrial stromal growth factor. Endocrinology 2002;143:2715-2721.

-16 Colvin JS, Feldman B, Nadeau JH, Goldfarb M, Ornitz DM: Genomic organization and embryonic expression of the mouse fibroblast growth factor 9 gene. Dev Dyn 1999;216:72-88.

17 Lin Y, Liu G, Wang F: Generation of an Fgf9 conditional null allele. Genesis 2006;44:150-154.

18 Deb K, Reese J, Paria BC: Methodologies to study implantation in mice. Methods Mol Med 2006;121:9-34.

19 Polesskaya A, Naguibneva I, Fritsch L, Duquet A, Ait-Si-Ali S, Robin P, Vervisch A, Pritchard LL, Cole P, HarelBellan A: CBP/p300 and muscle differentiation: no HAT, no muscle. EMBO J 2001;20:6816-6825.

20 Naruo K, Seko C, Kuroshima K, Matsutani E, Sasada R, Kondo T, Kurokawa T: Novel secretory heparinbinding factors from human glioma cells (glia-activating factors) involved in glial cell growth. Purification and biological properties. J Biol Chem 1993;268:2857-2864.

-21 Curtis Hewitt S, Goulding EH, Eddy EM, Korach KS: Studies using the estrogen receptor alpha knockout uterus demonstrate that implantation but not decidualization-associated signaling is estrogen dependent. Biol Reprod 2002;67:1268-1277.

-22 Curtis SW, Clark J, Myers P, Korach KS: Disruption of estrogen signaling does not prevent progesterone action in the estrogen receptor alpha knockout mouse uterus. Proc Natl Acad Sci U S A 1999;96:3646-3651.

23 Chuang PC, Sun HS, Chen TM, Tsai SJ: Prostaglandin E2 induces fibroblast growth factor 9 via EP3dependent protein kinase Cdelta and Elk-1 signaling. Mol Cell Biol 2006;26:8281-8292.

24 Wu MH, Lu CW, Chuang PC, Tsai SJ: Prostaglandin E2: the master of endometriosis? Exp Biol Med (Maywood) 2010;235:668-677.

25 Smith WL, DeWitt DL, Garavito RM: Cyclooxygenases: structural, cellular, and molecular biology. Annu Rev Biochem 2000;69:145-182.

26 Lim H, Paria BC, Das SK, Dinchuk JE, Langenbach R, Trzaskos JM, Dey SK: Multiple female reproductive failures in cyclooxygenase 2-deficient mice. Cell 1997;91:197-208.

27 Paria BC, Reese J, Das SK, Dey SK: Deciphering the cross-talk of implantation: advances and challenges. Science 2002;296:2185-2188.

-28 Matsumoto H, Ma WG, Daikoku T, Zhao X, Paria BC, Das SK, Trzaskos JM, Dey SK: Cyclooxygenase-2 differentially directs uterine angiogenesis during implantation in mice. J Biol Chem 2002;277:2926029267.

29 Paria BC, Huet-Hudson YM, Dey SK: Blastocyst's state of activity determines the "window" of implantation in the receptive mouse uterus. Proc Natl Acad Sci U S A 1993;90:10159-10162.

30 Murakami M, Simons M: Fibroblast growth factor regulation of neovascularization. Curr Opin Hematol 2008;15:215-220.

-31 Frontini MJ, Nong Z, Gros R, Drangova M, O’Neil C, Rahman MN, Akawi O, Yin H, Ellis CG, Pickering JG: Fibroblast growth factor 9 delivery during angiogenesis produces durable, vasoresponsive microvessels wrapped by smooth muscle cells. Nat Biotechnol 2011;29:421-427.

-32 Sweeney MD, Ayyadurai S, Zlokovic BV: Pericytes of the neurovascular unit: key functions and signaling pathways. Nat Neurosci 2016;19:771-783.

-33 Ornitz DM, Xu J, Colvin JS, McEwen DG, MacArthur CA, Coulier F, Gao G, Goldfarb M: Receptor specificity of the fibroblast growth factor family. J Biol Chem 1996;271:15292-15297.

-34 Hecht D, Zimmerman N, Bedford M, Avivi A, Yayon A: Identification of fibroblast growth factor 9 (FGF9) as a high affinity, heparin dependent ligand for FGF receptors 3 and 2 but not for FGF receptors 1 and 4. Growth Factors 1995;12:223-233. 


\section{Cellular Physiology Cell Physiol Biochem 2017;42:2318-2329 \begin{tabular}{l|l|l} 
and Biochemistry Published onlIne: August 17, 2017 & $\begin{array}{l}\text { C) } 2017 \text { The Author(s). Published by S. Karger AG, Basel } \\
\text { www.karger.com/cpb }\end{array}$ \\
\hline
\end{tabular}}

-35 Guillemot F, Zimmer C: From cradle to grave: the multiple roles of fibroblast growth factors in neural development. Neuron 2011;71:574-588.

-36 Wang H, Dey SK: Roadmap to embryo implantation: clues from mouse models. Nat Rev Genet 2006;7:185199.

-37 Hewitt SC, Li L, Grimm SA, Chen Y, Liu L, Li Y, Bushel PR, Fargo D, Korach KS: Research resource: wholegenome estrogen receptor alpha binding in mouse uterine tissue revealed by ChIP-seq. Mol Endocrinol 2012;26:887-898.

-38 Rubel CA, Lanz RB, Kommagani R, Franco HL, Lydon JP, DeMayo FJ: Research resource: Genome-wide profiling of progesterone receptor binding in the mouse uterus. Mol Endocrinol 2012;26:1428-1442.

39 Wang H, Ma WG, Tejada L, Zhang H, Morrow JD, Das SK, Dey SK: Rescue of female infertility from the loss of cyclooxygenase- 2 by compensatory up-regulation of cyclooxygenase- 1 is a function of genetic makeup. J Biol Chem 2004;279:10649-10658.

-40 Ruan YC, Guo JH, Liu X, Zhang R, Tsang LL, Dong JD, Chen H, Yu MK, Jiang X, Zhang XH, Fok KL, Chung YW, Huang H, Zhou WL, Chan HC: Activation of the epithelial Na+ channel triggers prostaglandin E(2) release and production required for embryo implantation. Nat Med 2012;18:1112-1117.

41 Brosens JJ, Salker MS, Teklenburg G, Nautiyal J, Salter S, Lucas ES, Steel JH, Christian M, Chan YW, Boomsma CM, Moore JD, Hartshorne GM, Sucurovic S, Mulac-Jericevic B, Heijnen CJ, Quenby S, Koerkamp MJ, Holstege FC, Shmygol A, Macklon NS: Uterine selection of human embryos at implantation. Sci Rep 2014;4:3894.

-42 Lim H, Ma L, Ma WG, Maas RL, Dey SK: Hoxa-10 regulates uterine stromal cell responsiveness to progesterone during implantation and decidualization in the mouse. Mol Endocrinol 1999;13:1005-1017.

43 Hyder SM, Stancel GM: Regulation of angiogenic growth factors in the female reproductive tract by estrogens and progestins. Mol Endocrinol 1999;13:806-811.

-44 Zammit C, Barnard R, Gomm J, Coope R, Shousha S, Coombes C, Johnston C: Altered intracellular localization of fibroblast growth factor receptor 3 in human breast cancer. J Pathol 2001;194:27-34.

45 Rotterud R, Fossa SD, Nesland JM: Protein networking in bladder cancer: immunoreactivity for FGFR3, EGFR, ERBB2, KAI1, PTEN, and RAS in normal and malignant urothelium. Histol Histopathol 2007;22:349363.

46 Zhou L, Yao LT, Liang ZY, Zhou WX, You L, Shao QQ, Huang S, Guo JC, Zhao YP: Nuclear translocation of fibroblast growth factor receptor 3 and its significance in pancreatic cancer. Int J Clin Exp Pathol 2015;8:14640-14648.

47 Murray MJ, Lessey BA: Embryo implantation and tumor metastasis: common pathways of invasion and angiogenesis. Semin Reprod Endocrinol 1999;17:275-290.

48 Nakajima T, Hayashi S, Iguchi T, Sato T: The role of fibroblast growth factors on the differentiation of vaginal epithelium of neonatal mice. Differentiation 2011;82:28-37.

49 Haffner-Krausz R, Gorivodsky M, Chen Y, Lonai P: Expression of Fgfr2 in the early mouse embryo indicates its involvement in preimplantation development. Mech Dev 1999;85:167-172.

-50 Arman E, Haffner-Krausz R, Chen Y, Heath JK, Lonai P: Targeted disruption of fibroblast growth factor (FGF) receptor 2 suggests a role for FGF signaling in pregastrulation mammalian development. Proc Natl Acad Sci U S A 1998;95:5082-5087. 